\title{
Safety and outcome of gastrostomy tube placement in patients with Loeys-Dietz syndrome
}

\author{
Pamela A. Frischmeyer-Guerrerio ${ }^{1}$, Gretchen MacCarrick ${ }^{2}$, Harry C. Dietz ${ }^{2,3}$, F. Dylan Stewart ${ }^{4}$ and \\ Anthony L. Guerrerio ${ }^{5^{*}}$
}

\begin{abstract}
Background: Loeys-Dietz syndrome (LDS) is a systemic connective tissue disease (CTD) associated with a predisposition for intestinal inflammation, food allergy, and failure to thrive, often necessitating nutritional supplementation via gastrostomy tube. Poor wound healing has also been observed in in some patients with CTD, potentially increasing the risk of surgical interventions. We undertook to determine the safety and efficacy of gastrostomy tube placement in this population.

Methods: We performed a retrospective cohort study of 10 LDS patients who had a total of 12 gastrostomy tubes placed.

Results: No procedural complications occurred, although one patient developed buried bumper syndrome in the near post-procedural time period and one patient had a small abscess at a surgical stitch. Most patients exhibited improvements in growth, with a median immediate improvement in BMI Z-score of 0.2 per month following the institution of gastrostomy tube feedings. Those with uncontrolled inflammation due to inflammatory bowel disease or eosinophilic gastrointestinal disease showed the least benefit and in some cases failed to demonstrate significant weight gain despite nutritional supplementation.
\end{abstract}

Conclusions: Gastrostomy tube placement (surgical or endoscopic) is a generally safe and a reasonable therapeutic option for patients with LDS despite their underlying CTD.

Keywords: PEG, Connective tissue disorder, LDS, G-tube, Gastrointestinal, Gl, Failure to thrive

\section{Background}

Over 200 disorders have been identified that affect the connective tissue, including a number of genetic disorders that result from single gene mutations. First described in 2005, Loeys-Dietz syndrome (LDS) is an autosomaldominant connective tissue disorder most commonly caused by mutations in the transforming growth factor $\beta$

\footnotetext{
* Correspondence: aguerrerio@jhmi.edu

${ }^{5}$ Department of Pediatrics, Division of Pediatric Gastroenterology, Hepatology and Nutrition, Johns Hopkins University School of Medicine, CMSC 2-116, 600 North Wolfe Street, Baltimore, MD 21287, USA

Full list of author information is available at the end of the article
}

receptor I (TGFBR1) and transforming growth factor $\beta$ receptor II (TGFBR2) genes (Type 1 and 2 LDS, respectively) $[1,2]$. LDS was initially characterized by aortic aneurysms and generalized arterial tortuosity, hypertelorism, and bifid uvula/cleft palate, although the phenotype was subsequently expanded to include a predilection for the development of food allergies, eosinophilic gastrointestinal disease (EGID), and inflammatory bowel disease (IBD) $[3,4]$.

Infants and children with LDS frequently present with failure to thrive. The cause is likely multifactorial and may include the impact of repeated surgical interventions and hospitalizations, increased baseline caloric expenditures in

(C) The Author(s). 2020 Open Access This article is licensed under a Creative Commons Attribution 4.0 International License, which permits use, sharing, adaptation, distribution and reproduction in any medium or format, as long as you give appropriate credit to the original author(s) and the source, provide a link to the Creative Commons licence, and indicate if changes were made. The images or other third party material in this article are included in the article's Creative Commons licence, unless indicated otherwise in a credit line to the material. If material is not included in the article's Creative Commons licence and your intended use is not permitted by statutory regulation or exceeds the permitted use, you will need to obtain permission directly from the copyright holder. To view a copy of this licence, visit http://creativecommons.org/licenses/by/4.0/ The Creative Commons Public Domain Dedication waiver (http://creativecommons.org/publicdomain/zero/1.0/) applies to the data made available in this article, unless otherwise stated in a credit line to the data. 
patients with inadequately treated asthma and eczema, and unrecognized food allergies and/or intestinal inflammation that result in both increased expenditures and decreased nutrient absorption. Indeed, LDS patients with concomitant food allergy have significantly lower BMI than both normal and children with LDS who do not have food allergy [3]. Additionally, many patients experience difficulty with oral intake due to jaw muscle weakness. Management of nutrition in patients with LDS generally follows traditional protocols. For patients with severe failure to thrive and/or significant allergies, a gastrostomy tube provides stable access. However, while gastrostomy tube placement is generally associated with a low rate of complications in pediatric patients $[5,6]$, the underlying connective tissue disorder in LDS may pose additional risks which would outweigh the benefits. We therefore undertook a retrospective cohort study of LDS patients treated at our institution to evaluate the safety and efficacy of gastrostomy tube placement in this patient population.

\section{Methods}

This study was approved by the University's institutional review board. We performed a retrospective cohort study of all patients with a genetically confirmed diagnosis of LDS Types 1 and 2 seen at our institution through December 12, 2017.

\section{Results}

The records of 182 Type 1 and 2 LDS patients were evaluated. Eleven (6\%) have undergone gastrostomy tube placement as part of their clinical care. Original records regarding gastrostomy tube placement were not available for one patient who has been excluded from further discussion. Patient characteristics are listed in Table 1. Two of the 10 patients underwent a second gastrostomy tube placement after the originally placed tube was removed (in both cases as a result of patient/family decision). Patient 2 had the second gastrostomy placed endoscopically at the original site. Patient 5 had the second gastrostomy placed at a new site. Half of the patients had Type 1 LDS and half were male. Six patients had allergic or gastrointestinal comorbidities including food allergy, EGID, or IBD. The indication for $10 / 12$ gastrostomy tube placements was failure to thrive. Three patients were less than 1 year of age at the time of placement

Table 1 Patient Characteristics

\begin{tabular}{|c|c|c|c|c|c|c|c|c|c|c|}
\hline Patient & $\begin{array}{l}\text { LDS } \\
\text { Type }\end{array}$ & Sex & Comorbiditiest & Technique* & $\begin{array}{l}\text { age at } \\
\text { placement§ }\end{array}$ & Indication & $\begin{array}{l}\text { BMl Z-score at } \\
\text { placement }\end{array}$ & $\begin{array}{l}\text { BMI } \triangle \text { Z- } \\
\text { score/ } \\
\text { month }\end{array}$ & $\begin{array}{l}\text { years } \\
\text { follow } \\
\text { up }\end{array}$ & $\begin{array}{l}\text { Most recent } \\
\text { BMI Z-score } \neq\end{array}$ \\
\hline 1 & 1 & $M$ & $\begin{array}{l}\text { FA, EGID, } \\
\text { crohns }\end{array}$ & PEG 14F & 10 & $\mathrm{FTT}$ & -2.32 & -0.37 & 10.4 & -6.90 \\
\hline 2.1 & 1 & M & & Open & $<1$ & $\begin{array}{l}\text { Poor } \\
\text { intake }\end{array}$ & -1.96 & -0.04 & 0.9 & \\
\hline 2.2 & & & & PEG 20F & 3 & FTT & -3.63 & 0.84 & 5.2 & -2.99 \\
\hline 3 & 1 & M & & Lap w/BIH & $<1$ & $\begin{array}{l}\text { FTT, poor } \\
\text { intake }\end{array}$ & -2.78 & 0.18 & 2.1 & -1.71 \\
\hline 4 & 1 & M & & Lap w/LIH & 7 & FTT & -7.04 & 0.45 & 0.7 & -3.45 \\
\hline 5.1 & 1 & F & FA, eczema & $\begin{array}{l}\text { Lap w/Nissen, Ladds } \\
\text { for malrotation }\end{array}$ & 8 & FTT & -2.10 & -0.36 & 0.7 & \\
\hline 5.2 & & & & Lap & 10 & FTT & -4.25 & 0.02 & 7.3 & -1.97 \\
\hline 6 & 2 & M & & Lap & 9 & FTT & -4.25 & 0.12 & 8.6 & 0.34 \\
\hline 7 & 2 & $\mathrm{~F}$ & FA, EGID, UC & PEG 14F & 13 & $\mathrm{FTT}$ & -2.53 & -0.25 & 1.1 & -3.96 \\
\hline 8 & 2 & F & FA, EGID & PEG 16F & 5 & $\mathrm{FTT}$ & -1.45 & -0.03 & 9.6 & -0.46 \\
\hline 9 & 2 & F & FA, EGID & $\begin{array}{l}\text { Open, Stamm w/ } \\
\text { Nissen }\end{array}$ & $<1$ & $\begin{array}{l}\text { Poor } \\
\text { intake }\end{array}$ & -1.56 & 0.29 & 13.7 & 0.54 \\
\hline 10 & 2 & F & EGID & PEG 20F & 7 & FTT & -5.40 & 0.78 & 0.6 & -0.80 \\
\hline Median & & & & & 7 & & -2.66 & 0.07 & 6.2 & -1.84 \\
\hline Minimum & & & & & $<1$ & & -7.04 & -0.37 & 0.6 & -6.90 \\
\hline Maximum & & & & & 13 & & -1.45 & 0.84 & 13.7 & 0.54 \\
\hline
\end{tabular}

Patients 2 and 5 had gastrostomy tubes placed twice

BMI Z-score from CDC growth chart; at ages less than 2 years old, the WHO weight/length Z-score was used

tFA food allergy; EGID eosinophilic GI disease; UC ulcerative colitis

*PEG Percutaneous endoscopic gastrostomy; Lap Laproscopic; BIH bilateral inguinal hernia repair; LIH Left inguinal hernia repair

$\S$ Age at placement rounded to nearest year

**in the immediate post-operative period

$\ddagger$ Most recent BMI Z-score or last BMI Z score prior to discontinuation of gastrostomy tube feeds 
and had poor oral intake as an indication. Gastrostomy tubes were placed at a median age of 7 years old (yo) and patients were followed for a median of 3.7 years (until the present time or tube discontinuation). Five of 12 placements were done endoscopically, with the remaining being placed surgically by a total of 8 Pediatric Surgeons/Gastroenterologists. The method of placement was at the discretion of the provider.

BMI Z-score based on CDC growth chart (or weight/length Z-score based on WHO growth chart for patients less than 2 years old) was calculated at a physician visit just prior to placement, and again at a physician visit after placement, but at least 2 months post-placement (median 6.7 months post, range 2.813.7 months), and are shown in Fig. 1. Median BMI (or weight/length) Z-score prior to placement was 2.7. Overall, median Z-score change after placement was 0.1 per month. Five patients had negative Z-score changes post-placement. Two of these patients discontinued gastrostomy feeds in the postoperative period prior to the first weight and length measurement (one of these patients had severe vomiting on an intact protein formula, and the tube was removed

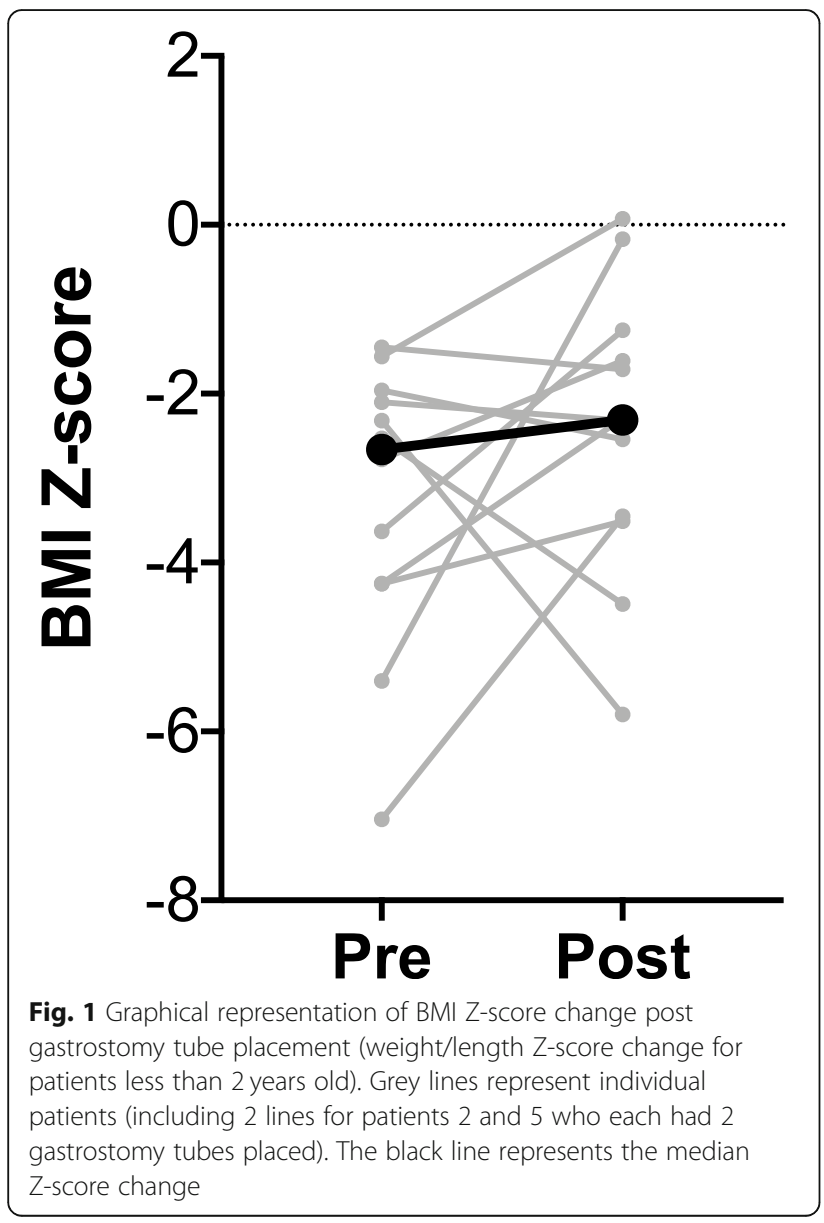

without a trial of an extensively hydrolyzed or elemental formula; the second patient unilaterally removed the gastrostomy tube halfway through the listed follow-up time). Two patients had severe, uncontrolled IBD. The last patient had EGID and continued eating a food known to trigger her EGID as confirmed by biopsy. Excluding these 5 patients, there was a median 0.3 improvement in $\mathrm{Z}$ score per month (range 0.0-0.8) after gastrostomy tube placement. Excluding only the two patients who elected to discontinue feeds through their gastrostomy tube, the $\mathrm{Z}$ score increased a median of 0.2 per month (range $0.4-0.8)$ in the immediate post-procedural time period.

After a median follow-up of 6.2 years (considering only follow-up after the second gastrostomy tube placement for the two patients who received two tubes), all patients had improvement in their BMI Z score over the time period they were receiving feeds through the gastrostomy tube, except for the two patients with IBD. Overall, the BMI Z-score improved a median of 0.2 per year (range - $1.3-7.7$ ) for this time period. $60 \%(7 / 12)$ of gastrostomy tube placements resulted in an increase in BMI Z-score in the short term post-operative period. Long-term, 70\% (7/ 10) had improvement in their BMI Z-score.

Evaluation of postoperative complications included infection, bleeding, perforation, or other complication. No procedural complications occurred during the endoscopic or surgical placement of the tubes. Patient 5 had a small abscess at a surgical suture 1 week post placement of her first gastrostomy tube, treated by incision and drainage. Patient 7 had buried bumper syndrome diagnosed 3 weeks after placement. Buried bumper occurs when pressure from the internal bumper leads to migration of the bumper out of the lumen and into the gastric wall along the tract [7]. It is typically considered a late complication of gastrostomy tube placement [8] but has been reported as early as 3 days to 3 weeks post placement $[9,10]$. Estimates of the incidence range up to $9 \%$ in adults [11] and from $2 \%$ to greater than $20 \%$ in children $[12,13]$. This patient presented with pain after the procedure that progressively worsened. Throughout this time, the outer bumper tension was appropriate, and the tube rotated easily. After 3 weeks a CT scan revealed the buried bumper. A guide wire was placed through the buried PEG tube and visualized in the stomach endoscopically, and the buried tube was removed. The tract was then dilated and a new tube was placed, both over the guidewire. Patient 6 had slow expansion of the gastrostomy site, without signs of gastric prolapse or infection, over months to years that eventually required surgical closure 8.6 years after 
placement. It is possible the underlying connective tissue disorder contributed to these complications, but we have no direct evidence of this.

\section{Discussion}

Gastrostomy tubes are known to be an effective means to supplement nutrition in children unable to sustain adequate growth via oral intake alone. However, the safety of this procedure in children with an underlying connective tissue disease is not known. Here, we report on the outcome of the placement of 12 gastrostomy tubes in 10 patients with Loeys-Dietz syndrome (LDS), an autosomal dominant connective tissue disease caused by mutations in genes in the TGF $\beta$ signaling pathway. LDS is a multisystem disorder associated with an increased propensity for allergic disease, EGID and IBD (both ulcerative colitis and crohns). We have previously demonstrated that the BMI Z-score of patients with LDS are significantly below 0; furthermore, the BMI Z-score of those with comorbid allergic or intestinal disease are significantly below those without these comorbidities [3]. As a result, many of the patients with immune-mediated disease often present with failure to thrive, necessitating supplemental feeding via gastrostomy tube. We found that all 12 tubes placed in this population resulted in no procedural complications. Post-placement, one patient had a small abscess at a surgical stitch and one patient suffered from buried bumper syndrome in the post-operative period, which occurs when excess tension between the internal and external bumpers causes ischemic necrosis of the gastric wall and the tube migrates, becoming lodged between the gastric wall and skin. A third patient had a widely patent/expanded gastrostomy site that required surgical closure. Overall, the procedure was safe in this patient population, whether done endoscopically or surgically.

Among patients who were receiving feeds through their gastrostomy tube, the median BMI (or weight/ length for patients less than 2 years old) $\mathrm{Z}$ score increased 0.2 per month of gastrostomy tube feedings in the immediate post-procedural time period. The three patients who used their gastrostomy tube but did not have improvement in their BMI Z-score all had ongoing intestinal inflammation (either IBD or EGID), emphasizing that while gastrostomy tubes can provide effective nutritional support, control of underlying inflammatory disease is essential. Long term, all patients using their gastrostomy tube had an increase in their BMI Z-score excepting those with IBD. The selection of formula used post-gastrostomy tube placement should take into account the increased incidence of food allergy and EGID in this population.

\section{Conclusion}

Given the data presented here, gastrostomy tubes can be placed in this population safely. Physicians can recommend placement of a gastrostomy tubes in an LDS patient when clinically indicated.

\section{Abbreviations}

$\mathrm{BIH}$ : Bilateral inguinal hernia repair; BMI: Body mass index; CDC: Centers for Disease Control; CTD: Connective tissue disease; EGID: Eosinophilic gastrointestinal disease; FA: Food Allergy; IBD: Inflammatory bowel disease; Lap: Laproscopic; LIH: Left inguinal hernia repair; LDS: Loeys-Dietz syndrome; PEG: Percutaneous endoscopic gastrostomy; UC: Ulcerative colitis; WHO: World Health Organization; yo: Years old

\section{Acknowledgements}

NA

\section{Authors' contributions}

All authors have read and approved the manuscript. Study conception and design: ALG, PAF-G. Data acquisition: ALG, PAF-G, GM, FDS. Analysis and data interpretation: ALG, PAF-G, FDS. Drafting of the manuscript: ALG, PAF-G, FDS. Critical revision: ALG, PAF-G, GM, FDS, HCD.

\section{Funding}

This work was supported in part by the Division of Intramural Research, NIAID, NIH (PAF-G), the Loeys-Dietz Syndrome Foundation (PAF-G, ALG, HCD), the National Marfan Foundation and Howard Hughes Medical Institute (HCD), and the NIH Mentored Research Development Award (1K08DK106463; ALG). These funding bodies played no role in the design of the study and collection, analysis, and interpretation of data and in writing the manuscript.

\section{Availability of data and materials}

The datasets generated and/or analyzed during the current study are not publicly available because they are medical records and therefore protected $\mathrm{PHI}$, but are available from the corresponding author on reasonable request.

\section{Ethics approval and consent to participate}

All procedures performed in studies involving human participants were in accordance with the ethical standards of the institutional and/or national research committee and with the 1964 Helsinki declaration and its later amendments or comparable ethical standards. This study was approved by the Johns Hopkins University's institutional review board. Informed consent This study was granted a waiver of consent as a retrospective chart review by the Johns Hopkins University's institutional review board (IRB00096462) for individual participants included in the study.

\section{Consent for publication}

Patients/Guardians have consented to publication in writing under protocol approved by the National Institutes of Health (15-I-0162).

\section{Competing interests}

The authors declare that they have no competing interests.

\section{Author details}

${ }^{1}$ The Laboratory of Allergic Diseases, National Institutes of Allergy and Infectious Diseases, Bethesda, MD, USA. ${ }^{2}$ McKusick-Nathans Institute of Genetic Medicine, Johns Hopkins University School of Medicine, Baltimore, MD, USA. ${ }^{3}$ Howard Hughes Institute, Chevy Chase, MD, USA. ${ }^{4}$ Department of Surgery, Westchester Medical Center, Section of Pediatric Surgery, Maria Fareri Children's Hospital, Valhalla, NY, USA. ${ }^{5}$ Department of Pediatrics, Division of Pediatric Gastroenterology, Hepatology and Nutrition, Johns Hopkins University School of Medicine, CMSC 2-116, 600 North Wolfe Street, Baltimore, MD 21287, USA.

Received: 7 November 2019 Accepted: 3 March 2020

Published online: 12 March 2020

\section{References}

1. Loeys BL, Chen J, Neptune ER, Judge DP, Podowski M, Holm T, et al. A syndrome of altered cardiovascular, craniofacial, neurocognitive and skeletal 
development caused by mutations in TGFBR1 or TGFBR2. Nat Genet. 2005; 37(3):275-81.

2. Loeys BL, Schwarze U, Holm T, Callewaert BL, Thomas GH, Pannu H, et al. Aneurysm syndromes caused by mutations in the TGF-beta receptor. N Engl J Med. 2006;355(8):788-98.

3. Frischmeyer-Guerrerio PA, Guerrerio AL, Oswald G, Chichester K, Myers L, Halushka MK, et al. TGFbeta receptor mutations impose a strong predisposition for human allergic disease. Sci Transl Med. 2013;5(195): 195ra94.

4. Guerrerio AL, Frischmeyer-Guerrerio PA, Huang C, Wu Y, Haritunians T, McGovern DPB, et al. Increased prevalence of inflammatory bowel disease in patients with mutations in genes encoding the receptor subunits for TGFbeta. Inflamm Bowel Dis. 2016;22(9):2058-62.

5. Fortunato JE, Troy AL, Cuffari C, Davis JE, Loza MJ, Oliva-Hemker M, et al. Outcome after percutaneous endoscopic gastrostomy in children and young adults. J Pediatr Gastroenterol Nutr. 2010;50(4):390-3.

6. Sandberg F, Viktorsdottir MB, Salo M, Stenstrom P, Arnbjornsson E. Comparison of major complications in children after laparoscopy-assisted gastrostomy and percutaneous endoscopic gastrostomy placement: a metaanalysis. Pediatr Surg Int. 2018;34(12):1321-7.

7. Klein S, Heare BR, Soloway RD. The "buried bumper syndrome": a complication of percutaneous endoscopic gastrostomy. Am J Gastroenterol. 1990;85(4):448-51

8. Schrag SP, Sharma R, Jaik NP, Seamon MJ, Lukaszczyk JJ, Martin ND, et al. Complications related to percutaneous endoscopic gastrostomy (PEG) tubes. A comprehensive clinical review. J Gastrointestin Liver Dis. 2007;16(4): 407-18

9. Azevedo R, Caldeira A, Banhudo A. Early presentation of buried bumper syndrome. GE Port J Gastroenterol. 2018;25(3):154-6.

10. Geer W, Jeanmonod R. Early presentation of buried bumper syndrome. West J Emerg Med. 2013;14(5):421-3.

11. Lee TH, Lin JT. Clinical manifestations and management of buried bumper syndrome in patients with percutaneous endoscopic gastrostomy. Gastrointest Endosc. 2008;68(3):580-4.

12. Kohler H, Lang T, Behrens R. Buried bumper syndrome after percutaneous endoscopic gastrostomy in children and adolescents. Endoscopy. 2008; 40(Suppl 2):E85-6.

13. Segal D, Michaud L, Guimber D, Ganga-Zandzou PS, Turck D, Gottrand F. Late-onset complications of percutaneous endoscopic gastrostomy in children. J Pediatr Gastroenterol Nutr. 2001;33(4):495-500.

\section{Publisher's Note}

Springer Nature remains neutral with regard to jurisdictional claims in published maps and institutional affiliations.

Ready to submit your research? Choose BMC and benefit from:

- fast, convenient online submission

- thorough peer review by experienced researchers in your field

- rapid publication on acceptance

- support for research data, including large and complex data types

- gold Open Access which fosters wider collaboration and increased citations

- maximum visibility for your research: over $100 \mathrm{M}$ website views per year

At $\mathrm{BMC}$, research is always in progress.

Learn more biomedcentral.com/submissions 